https://helda.helsinki.fi

\title{
Matches and mismatches between conservation investments and biodiversity values in the European Union
}

\section{Sanchez-Fernandez, David}

2018-02

Sanchez-Fernandez , D , Abellan , P , Aragon , P , Varela , S \& Cabeza , M 2018 , ' Matches and mismatches between conservation investments and biodiversity values in the European Union ' , Conservation Biology , vol. 32 , no. 1 , pp. 109-115 . https://doi.org/10.1111/cobi.12977

http://hdl.handle.net/10138/325673

https://doi.org/10.1111/cobi.12977

unspecified

acceptedVersion

Downloaded from Helda, University of Helsinki institutional repository.

This is an electronic reprint of the original article.

This reprint may differ from the original in pagination and typographic detail.

Please cite the original version. 


\section{Matches and mismatches between conservation investments and biodiversity values in the European Union}

David Sánchez-Fernández ${ }^{1}$, Pedro Abellán², Pedro Aragón ${ }^{3}$, Sara Varela ${ }^{4}$ \& Mar Cabeza ${ }^{5}$

${ }^{1}$ Instituto de Ciencias Ambientales. Universidad de Castilla-La Mancha. Toledo, Spain.

${ }^{2}$ Department of Biology, Queens College, City University of New York, 65-30 Kissena Blvd, Flushing, New York, NY 11367, USA.

${ }^{3}$ Departamento de Biogeografía y Cambio Global, Museo Nacional de Ciencias Naturales (CSIC). José Gutiérrez Abascal, 2. E-28006 Madrid, Spain.

${ }^{4}$ Departamento de Ciencias de la Vida, Edificio de Ciencias, Campus Externo, Universidad de Alcalá, E-28805 Alcalá de Henares, Madrid, Spain.

${ }^{5}$ Metapopulation Research Centre, Department of Biosciences, University of Helsinki, PO Box 65 (Viikinkaari 1), 00014 Helsinki, Finland.

Correspondence to: David Sánchez-Fernández. Instituto de Ciencias Ambientales. Universidad de Castilla-La Mancha. Campus Tecnológico de la Fábrica de Armas, 45071. Toledo, Spain. e-mail: David.SFernandez@uclm.es

This article has been accepted for publication and undergone full peer review but has not been through the copyediting, typesetting, pagination and proofreading process, which may lead to differences between this version and the Version of Record. Please cite this article as doi: 10.1111/cobi.12977.

This article is protected by copyright. All rights reserved. 
Short title: EU conservation efforts

Keywords: conservation policy, endemism, funds allocation, LIFE program, Natura 2000, species of Community interest, species richness

Word count: 4072

\section{Abstract}

Recently, the European Commission adopted a new strategy to halt the loss of biodiversity. Member states are expected to favour a more effective collection and redistribution of European Union (EU) funds under the current Multiannual Financial Framework for 2014-2020. Because of the large spatial variation in the distribution of biodiversity and conservation needs at the continental scale, EU instruments should ensure that countries with higher biodiversity values get more funds and resources for the conservation of this biodiversity than other countries. We assess the association between conservation investments and biodiversity values across the member states, accounting for a variety of conservation investment indicators, taxonomic groups (including groups of plants, vertebrates and invertebrates) and biodiversity value indicators. In general, we have found good overall associations between conservation investments and biodiversity variables. However, some mismatches were found in countries receiving more (or less) investments than expected based on their biodiversity values. We also found that the extensive use of birds as unique indicators of conservation effectiveness may be misleading. These results can provide insight to policymakers to aid future decisions regarding funding allocation, allowing a better redistribution of EU funds.

\section{Introduction}

Europe is one of the most intensively studied areas of the world with respect to its biota (Hawksworth \& Bull 2008) and contains approximately 1500 vertebrate species, 20-25,000 species of vascular plants and well over 100,000 invertebrate species (IUCN European Red List 2010). In addition to the high diversity of European flora and fauna, a large proportion of European species

This article is protected by copyright. All rights reserved. 
can be considered as endemic to the region (IUCN European Red List 2010). However, European landscapes have been subjected to an almost unparalleled level of human disturbance and industrial development (Hawksworth \& Bull 2008).

In 2011, the European Commission adopted a new strategy to halt the loss of biodiversity and improve the state of Europe's species, habitats, ecosystems and the services they provide over the next decade (i.e., the so-called EU Biodiversity Strategy to 2020; European Commission 2011). Achieving the objectives of this strategy will depend on legislative regulations and the availability and efficient use of financial resources (Kettunen et al. 2009). However, as funding is limited, the Commission and Member States are expected to favour an effective collection and redistribution of European Union (EU) funds under the Multiannual Financial Framework for 2014-2020 (European Commission 2014). Thus, although motivations for conservation can be diverse, EU instruments should ensure that countries with higher biodiversity values (e.g., species richness, endemicity, etc) get more funds and spatial resources for the conservation of this biodiversity than other countries.

Most studies addressing the fit of EU conservation investments focus on the coverage of species mostly vertebrate groups - by the Natura 2000 network (Popescu et al. 2014; Maiorano et al. 2015; Kukkala et al. 2016), a crucial conservation instrument across the EU. Such assessments have found that while there are some gaps in coverage, the network covers all vertebrate species listed in the Directives to varying extents (Kukkala et al. 2016). Only recently have a few studies attempted to link economic investments to spatial biodiversity values at European scale, but they have often been limited to single taxa (see Lung et al. 2014 for birds) or specific funding programmes (see Hermoso et al. 2017 for an assessment of the LIFE-Nature programme using threatened species), providing only partial pictures. To our knowledge, no comprehensive and multi-taxa assessment of complementary conservation investments has been conducted, and important assessment gaps exist for plants and invertebrates, the most species-rich taxa included in the Habitat Directive.

Our aim here was not to study or discuss whether the current amount of financial support in the EU is (or is not) sufficient to preserve biodiversity in Europe. Instead, we examine the extent to which 
existing funds and resources are well aligned with biodiversity conservation needs, and what variables can explain deviances from the expected values. We thus estimated the association between conservation investments (both economic and spatial resources) and biodiversity values (species richness, endemicity, and community interest species) across member states, accounting for a variety of conservation investment indicators, taxonomic groups and biodiversity value indicators.

\section{Methods}

We used linear regressions to assess the relationship between biodiversity (explanatory) and conservation investments (response) variables. This study was conducted at the member-state level, and all biodiversity and conservation resource data were at this spatial resolution (see Supporting Information).

\section{Biodiversity data}

For each country, we used the data provided by Essl et al. (2013) on the total number of native (NS) and nationally endemic (NE) from nine taxonomic groups: two plant groups (vascular plants and bryophytes), five vertebrate groups (birds, mammals, reptiles, amphibians and freshwater fish), and two invertebrate groups (dragonflies and grasshoppers) (see Supporting Information). We also calculated the total number of species of Community interest (NSCl) per country, using the total number of species included in the main European Directives regarding biodiversity conservation (not only for these nine taxonomic groups). Specifically, we considered the species included in Annex I of the Birds Directive (79/409/EEC) along with the species included in Annex II of the Habitat Directive (92/43/EEC). These data were obtained from "Reporting from EU Member States under Article 17 of the Habitats Directive to the European Commission. Compiled by EEA and ETC/BD, 2014, date of delivery (date sent to the Data Service): February 2015" and "Reporting from EU Member States under Article 12 of the Birds Directive to the European Commission. Compiled by EEA, ETC/BD and European Red List of Birds Consortium, 2014-2015".

This article is protected by copyright. All rights reserved. 


\section{Conservation investments}

We considered both direct and indirect measures of conservation investment at European scale, including three groups of dependent variables describing quantitative area protection, economic effort, and conservation research projects per country.

i) The Natura 2000 network is the most important initiative for biodiversity conservation in Europe (Gaston et al. 2008). As a measure of the spatial resources invested in biodiversity conservation, we used the total surface area of each country included in the Natura 2000 network (hereafter N2000) and its proportion in relation to the country's area as a percentage (hereafter \%N2000). This network includes sites designated under the Birds Directive (Special Protection Areas, SPAs) and the Habitats Directive (Sites of Community Importance, SCls, and Special Areas of Conservation, SACs). We focused on the non-marine part of N2000. The existing N2000 sites cover nearly $18 \%$ of the EU land territory (European Environment Agency 2012). For each country, we used 6 variables associated with N2000: total surface area and percentage (\%) covered by SACs and SCls (hereafter all SACs), by SPAs and by all N2000-designated sites.

ii) Agri-environment schemes (AES) are a major source of nature conservation funding within the EU. AES were designed partly to reduce the ongoing declines of many species of conservation concern that depend on agricultural management. The total amount of public expenditure on AES in each EU Member State for 2007-2013 were obtained from Batáry et al. (2015).

iii) LIFE and LIFE+ programmes. The objective of LIFE is to foster the implementation of EU environmental policies by co-financing pilot projects with European added value, particularly in relation to the Habitats and Birds Directives. For each country, we used data on the number of total LIFE projects (NLP), the number of LIFE Nature and LIFE+ Nature and Biodiversity components projects (NLNP) to date and the total investments (in millions of $€$ ) (TIL and TILN), as well as the investments that have been contributed by the EU (in millions of $€$ ) (EUIL and EUILN). We focused on LIFE Nature and LIFE+ Nature and Biodiversity projects because of the three components of the LIFE programme (i.e., Nature and Biodiversity, Environment Policy and Governance, and Information and

This article is protected by copyright. All rights reserved. 
Communication), this is one the most directly related to biodiversity conservation. Data were downloaded from http://ec.europa.eu/environment/life/countries/index.htm

While we present results for all variables in the supplementary material (Supporting Information), given that many of the variables are highly correlated, we focus on 4 of the 13 variables in the main results section. We selected at least one variable of each one of the three groups of dependent variables. All unconsidered variables were significantly correlated (Spearman rank correlations $p<0.05$ and $r_{s}>0.6$ with at least one of the selected ones; see Supporting Information). We selected AES, the total surface area of the Natura 2000 network (N2000), as it correlated with SAC and SPA; $\% \mathrm{~N} 2000$, as it correlated with \%SCA and \%SPA; and NLP, as it was highly correlated with all variables related to LIFE projects.

\section{Other variables}

We also considered other co-variates that could explain departures from the relationship between biodiversity values and investments. These include four variables describing the size, wealth, conservation efficiency and scientific production per country. Notably, we used country area $\left(\mathrm{km}^{2}\right)$, the gross domestic product (GDP), the index of sufficiency of member states' proposals for sites designated under the habitats directive (SFS), and the scientific production of each country in conservation biology (SciProd).

GDP indicates the economic health of the different member states. When corrected by purchasing power standards, it accounts for differences in price levels between nations (Eurostat 2012a). SFS measures the extent to which the Sites of Community Importance proposed by the member states adequately cover the species and habitats listed in Annexes I and II of the habitats directive. A value of $100 \%$ indicates the sufficiency of the proposals for all Annex I terrestrial habitat types and Annex II terrestrial species of Community interest occurring in a member state's territories (Eurostat 2012b). Finally, SciProd was used as an indicator of research background in each country. An active conservation scientific community can potentially lead to more conservation investments either through funding applications (LIFE projects) to conduct applied research in conservation areas, or

This article is protected by copyright. All rights reserved. 
through research outcomes leading to conservation effectiveness appraisals and larger conservation targets. SciProd was calculated as the number of scientific publications found in the ISI Web of Knowledge database per country (using country affiliation of any coauthors) from 1980 to 2017, including in the search the combination of terms "Biodiversity Conservation" OR "Conservation Biology".

\section{Analysis}

Linear regressions between each biodiversity variable (for all taxa jointly and separately for each taxonomic group) and those variables related to conservation investments were used. As a complementary analysis, we grouped taxa into birds and non-birds groups and these data were regressed with the surface of SAC and SPA sites separately. We applied a hard Bonferroni correction for multiple comparisons to assess significance (Quinn \& Keough 2002). Residuals were checked for normality, and variables were transformed (using the box-cox transformation) when necessary (Quinn \& Keough 2002).

We explored the linear relationships between the residuals of the significant regressions (N2000 NS, NLP NS, AES NS, N2000 NE, NLP NE, N2000 NSI, NLP NSCI) and the four variables described above (i.e., area $\left(\mathrm{km}^{2}\right), \mathrm{GDP}, \mathrm{SFS}$ and SciProd. First, we ran individual lineal regressions to understand the relationships between residuals and the independent explanatory variables. Subsequently, we programmed an AIC stepwise-regression in order to have a final multivariate model for each case. We used the 'stats' R package for all the calculations (R Core Team, 2015).

\section{Results}

The total Natura 2000 surface area and the expenditure on LIFE projects (NLP) were positively related to all indicators of biodiversity value (NS, NE, NSCI) when all groups were analysed jointly (see Table 1 and Fig. 1). Expenditure on AES was significantly related only with NS (Table 1). For all significant relationships, we systematically identified some countries (Portugal, Slovakia, Hungary, and particularly Greece and the Czech Republic) that received less funds and resources than would 
be expected given their biodiversity (endemic, community interest and total species richness), while others (France, Finland, and particularly Germany and Great Britain) showed the opposite trend (see Fig. 1).

Residual variance of the relationships N2000 - biodiversity were tightly related to the area of the country (53-70\% of the residuals' deviance) (Supporting Information). The relationship was also positive for SFS and SciProd when variables were analysed individually. However, when combined with area in a final model, their coefficients were not significant. On the other hand, residuals of the significant relationships among NLP and biodiversity values were mainly explained by SciProd (40$68 \%$ of the residuals' deviance). Area and GDP were also positively related with NLP (Supporting Information). Lastly, residuals of the relationship between AES and NS were mainly explained by SciProd (35.65\% of the residuals' deviance) (Supporting Information).

Similarly, when the results were analysed at individual taxonomic levels, the strongest positive associations were found for NLP, being significant for all groups except fishes and bryophytes. The most significant positive associations between conservation investment variables were found for birds (except NE with AES). Regressions between biodiversity variables separately for birds and protected areas designated under Birds Directive (SPAs) and non-birds taxa and the area designated under Habitat Directive ( $\mathrm{SCl}$ and SAC) were almost identical than those obtained using the Natura 2000 network (Supporting Information).

\section{Discussion}

We analysed the correlations between economic efforts and biodiversity values at the scale of the entire EU and our results indicate that, in general terms, biodiversity values and indicators of conservation investment are aligned. Concretely, our results show that the Natura 2000 total surface area and LIFE projects funding are reasonably well aligned with species richness for all, endemic and European Community interest species. This congruence of results could be expected as all these biodiversity variables, except NT, are correlated at EU scale (especially NS and NSCl; see Supporting Information).

This article is protected by copyright. All rights reserved. 
In spite of these general patterns, we detected that some countries (e.g., Portugal, Slovakia, Hungary, and particularly Greece and the Czech Republic) have received less funds and spatial resources than would be expected given their biodiversity values. Indeed, a number of studies have demonstrated the lack of effectiveness of Natura 2000 networks in some of these countries (Dimitrakopoulos et al. 2004; Papageorgiou \& Vogiatzakis 2006; Abellán \& Sánchez-Fernández 2015), which might be related to insufficient funding or an inefficient allocation of conservation efforts in these areas.

We also found that the residual variance that could not be explained by the biodiversity variables considered here was in fact partially explained by other factors. Larger countries tend to have more Natura 2000 areas than the expected given their biodiversity values. This result is reflecting an unavoidable conflict of interest between different land uses by humans and availability of space, which is relaxed for larger countries. This trade-off should be stronger for countries with medium to high biodiversity values but relatively smaller sizes, such as Austria, Slovakia, Greece and Portugal in Europe. These results are especially interesting in the framework of recent mandate by the European Commission calling for a "fitness check" of the Birds and Habitat Directives (European Commission 2015).

On the other hand, countries with more scientific production receive more Life Projects and more funds for species conservation in agricultural environments than the expected given their biodiversity values. Several non-exclusive explanations can account for this pattern. The most obvious explanation is that successful applications for LIFE projects are merely due to a higher number of research applications of high quality submitted from countries with a longer tradition in ecological research, which would unavoidably yield the observed pattern (Popescu et al. 2014). It is also likely that those countries with less national budget destined to biodiversity conservation are more active in seeking funding from LIFE program (Nita et al. 2016). Yet a number of Member States lack the capacity to apply, mobilise and use available funds (Kettunen et al. 2009), potentially conflating some of our outcomes: deviations from expectations may both be due to lack of funding allocation, or fund absorption problems. This is a challenge for the European Commission since its

This article is protected by copyright. All rights reserved. 
funding for biodiversity conservation should involve a trade-off between providing resources for less developed countries while maintaining other reinforced. To accomplish this, and likely avoid this unbalanced situation, the Cohesion Fund during the 2014-2020 period is providing additional investments mostly for underfunded member states (e.g., Bulgaria, Croatia, Cyprus, the Czech Republic, Estonia, Greece, Hungary, Latvia, Lithuania, Malta, Poland, Portugal, Romania, Slovakia and Slovenia).

Further, there are important differences across taxonomic groups: birds show the clearest relationship between conservation investments and biodiversity value, while amphibians, mammals, fishes and non-conspicuous species (bryophytes and insects) show less significant relationships than when all groups were used jointly. This is not surprising as birds are the 'star group' in conservation biology, especially at the EU. Indeed, they have their "own European directive" that allows for funding LIFE projects and the declaration of Special Protection Areas included in the Natura 2000 network. Accordingly, Maiorano et al. (2015) showed that the N2000 network is more effective in protecting birds than other vertebrate groups. Our results are also consistent with those from Lung et al. (2014), who found that the allocation of conservation funds at the EU level was well aligned with current (but not future) conservation priorities in Europe using bird distributions as indicators of biodiversity value.

There are other relevant conservation investment sources that we have not accounted for, both at the national and EU levels. At the EU level, the most important include the Cohesion Fund, which provides funding for projects involving the environment and the trans-European network infrastructure. However, these sources of funding do not allow the share directed to biodiversity actions to be disentangled from other attributions and thus were not used here. Furthermore, some of the measures and projects developed with these funding programmes have been criticized, with arguments suggesting a high ecological impact of some of them (Nilsson et al. 2012). Here, we did not take into account nationally designated areas or national investments in conservation; therefore, we cannot discuss whether the current amount of financial support is sufficient to preserve biodiversity in each European country. In the same way, we did not consider the number of threatened species at any spatial scale. The hypothesis that EU resources give priority to continental 
needs (threatened species at European scale) relative to both nationally or globally threatened species (see Hermoso et al. 2017) could be tested in further researches. Additionally, it should be noted that other motivations for conservation not directly related to biodiversity value (e.g., restore disturbed communities; restore threatened species populations, etc.) could have some role in the allocation of funds. Indeed, measures of habitat diversity could also be used as biodiversity variable besides species richness. Nevertheless, we found significant correlations $(p<0.01)$ between the richness of habitats of Community importance (i.e. those included in the Annex I of the Habitats Directive) and three out of the four species richness indicators (Supporting information), especially clear in the case of total species richness $(r=0.83)$. This result suggests that using other measures of biodiversity could provide similar results as those obtained from species richness as indicators.

In summary, we found overall good associations between biodiversity value and conservation investment. However, other two important messages also arise from our study: i) conservation investments (mainly Natura 2000 total surface area and LIFE projects) are reasonably well aligned with species richness for all, endemic and European Community interest species, and ii) the extensive use of birds as indicators of conservation effectiveness may be misleading. Our results may also be useful for detecting those countries that are not taking sufficient advantage of European funds and thus may provide insight to policymakers for future decisions regarding funding allocation.

This would allow a better redistribution of EU funds under the Multi-annual Financial Framework for 2014-2020, avoiding unnecessary redundancy of efforts in different countries and the loss of biodiversity in Europe in the near future.

\section{Acknowledgments}

DS-F was supported by a post-doctoral contract funded by Universidad de Castilla-La Mancha and the European Social Fund (ESF). PAr was supported by a 'Ramón y Cajal' contract (RYC-2011-07670) from the Spanish Ministry of Economy and Competitiveness (MINECO). SV is supported by a postdoctoral contract funded by Universidad de Alcalá. MC is supported by the Academy of Finland (project \# 257686). This work was partly funded by the project CGL2014-56416-P (MINECO).

This article is protected by copyright. All rights reserved. 


\section{Literature Cited}

Abellán P, Sánchez-Fernández D. 2015. A gap analysis comparing the effectiveness of Natura 2000 and national protected area networks in representing European amphibians and reptiles. Biodiversity and Conservation 24: 1377-1390.

Batáry P, Dicks LV, Kleign D, Sutherland WJ. 2015. The role of agri-environment schemes in conservation and environmental management. Conservation Biology 29:1006-1016.

Dimitrakopoulos PG, Memtsas D, Troumbis AY. 2004. Questioning the effectiveness of the Natura 2000 special areas of conservation strategy: the case of Crete. Global Ecology and Biogeography 13: 199-207.

Essl F, Moser D, Dirnbvock T, Dullinger S, Milasowszky N, Winter M, Rabitsch W. 2013. Native, alien, endemic, threatened, and extinct species diversity in European countries. Biological Conservation 164: 90-97.

European Environment Agency. 2012. Protected areas in Europe: an overview. EEA Report 5/2012, Copenhagen. Available from http://www.eea.europa.eu/publications/protected-areas-in-europe2012 (accessed January 2016).

European Commission. 2011. Our life insurance, our natural capital: an EU biodiversity strategy to 2020. Communication from the Commission to the European Parliament, the Council, the Economic and Social Committee and the Committee of the Regions. COM/2011/244 (accessed June 2016).

This article is protected by copyright. All rights reserved. 
European Commission. 2015. Communication from the commission to the European Parliament, the council, the European economic and social committee and the committee of the regions. Regulatory Fitness and Performance Programme (REFIT): State of Play and Outlook. COM/2014/368 (accessed June 2016).

European Commission. 2014. Commission implementing decision of 19 March 2014 on the adoption of the LIFE multiannual work programme for 2014-17. 2014/203/EU (accessed March 2016).

Eurostat. 2012a. Gross domestic product at market prices. Available from http://epp.eurostat.ec.europa.eu/tgm/table.do?tab=table\&init=1\&plugin=1\&language=en\&pcode=t ec00001 (accessed January 2016).

Eurostat. 2012b. Sufficiency of sites designated under the EU Habitats directive. Available from http://epp.eurostat.ec.europa.eu/tgm/table.do?tab=table\&init=1\&plugin=1\&language=en \&pcode=t sdnr210 (accessed January 2016).

Gaston KJ, Jackson SF, Nagy A, Cantú-Salazar L, Johnson M. 2008. Protected areas in Europe. Annals of the New York Academy of Sciences 1134: 97-119.

Hawksworth DL, Bull AT. 2008. Biodiversity and conservation in Europe. Topics in Biodiversity and Conservation Series, vol. 7, Springer, The Netherlands.

Hermoso V, Clavero M, Villero D, Brotons LL. 2017. EU's conservation efforts need more strategic investment to meet continental commitments. Conservation Letters 10: 231-237.

This article is protected by copyright. All rights reserved. 
IUCN European Red List. 2010. Available from

http://ec.europa.eu/environment/nature/conservation/species/redlist/index en.htm

(accessed January 2016).

Kukkala AS, Arponen A, Maiorano L, Moilanen A, Thuiller W, Toivonen T, Zupan L, Brotons LL, Cabeza M. 2016. Matches and mismatches between national and EU-wide priorities: examining the Natura 2000 network in vertebrate species conservation. Biological Conservation 198: 193-201.

Kettunen M, Baldock D, Adelle C, Cooper T, Farmer M, Hart K, Torkler P. 2009. Biodiversity \& The EU Budget: making the case for conserving biodiversity. A report commissioned by the World Wide Fund for Nature (WWF) to the Institute for European Environmental Policy (IEEP), Brussels. Available from http://www.wwf.gr/images/pdfs/WWF_Biodiversity\%20and\%20EU\%20budget.pdf (visited June 25, 2016).

Lung T, Meller L, Van Teeffelen AJA, Thuiller W, Cabeza M. 2014. Biodiversity funds and conservation needs in the EU under climate change. Conservation Letters 7: 390-400.

Maiorano L, Amori G, Montemaggiori A, Rondini C, Santini L, Saura S, Boitani L. 2015. On how much biodiversity is covered in Europe by national protected areas and by the Natura2000 network: insights from terrestrial vertebrates. Conservation Biology 29: 986-995.

Nilsson M, Zamparutti T, Petersen J, Nykvist B, Rudberg P, McGuinn J. 2012. Understanding policy coherence: analytical framework and examples of sector-environment policy interactions in the EU. Environmental Policy and Governance 22: 395-423.

This article is protected by copyright. All rights reserved. 
Nita A, Rozylowicz L, Manolache S, Maria Ciocanea C, Viorica Miu I, Popescu VD. 2016. Collaboration Networks in Applied Conservation Projects across Europe. PLoS ONE 11:e0164503.

Papageorgiou K, Vogiatzakis IN. 2006. Nature protection in Greece: an appraisal of the factors shaping integrative conservation and policy effectiveness. Environmental Science \& Policy 9: 476-486.

Popescu VD, Rozylowicz L, Niculae IM, Cucu AL, Hartel T. 2014. Species, Habitats, Society: An Evaluation of Research Supporting EU's Natura 2000 Network. PLoS ONE 9(11): e113648.

Quinn GP, Keough MJ. 2002. Experimental Design and data Analysis for Biologist. Cambridge University Press. Cambridge.

R Core Team (2015). R: A language and environment for statistical computing. R Foundation for Statistical Computing, Vienna, Austria. URL http://www.R-project.org/.

Table 1. Results of the simple regression between biodiversity variables and those related to funds and resources for biodiversity conservation.

${ }^{a}$ Total surface area $\left(\mathrm{km}^{2}\right)$ covered by the Natura 2000 network.

${ }^{b}$ Percentage of the total surface of each country covered by Natura 2000 network.

${ }^{c}$ The number of LIFE projects.

${ }^{d}$ Public expenditure on agri-environment schemes (AES).

This article is protected by copyright. All rights reserved. 
*Significant relationship after a Bonferroni correction.

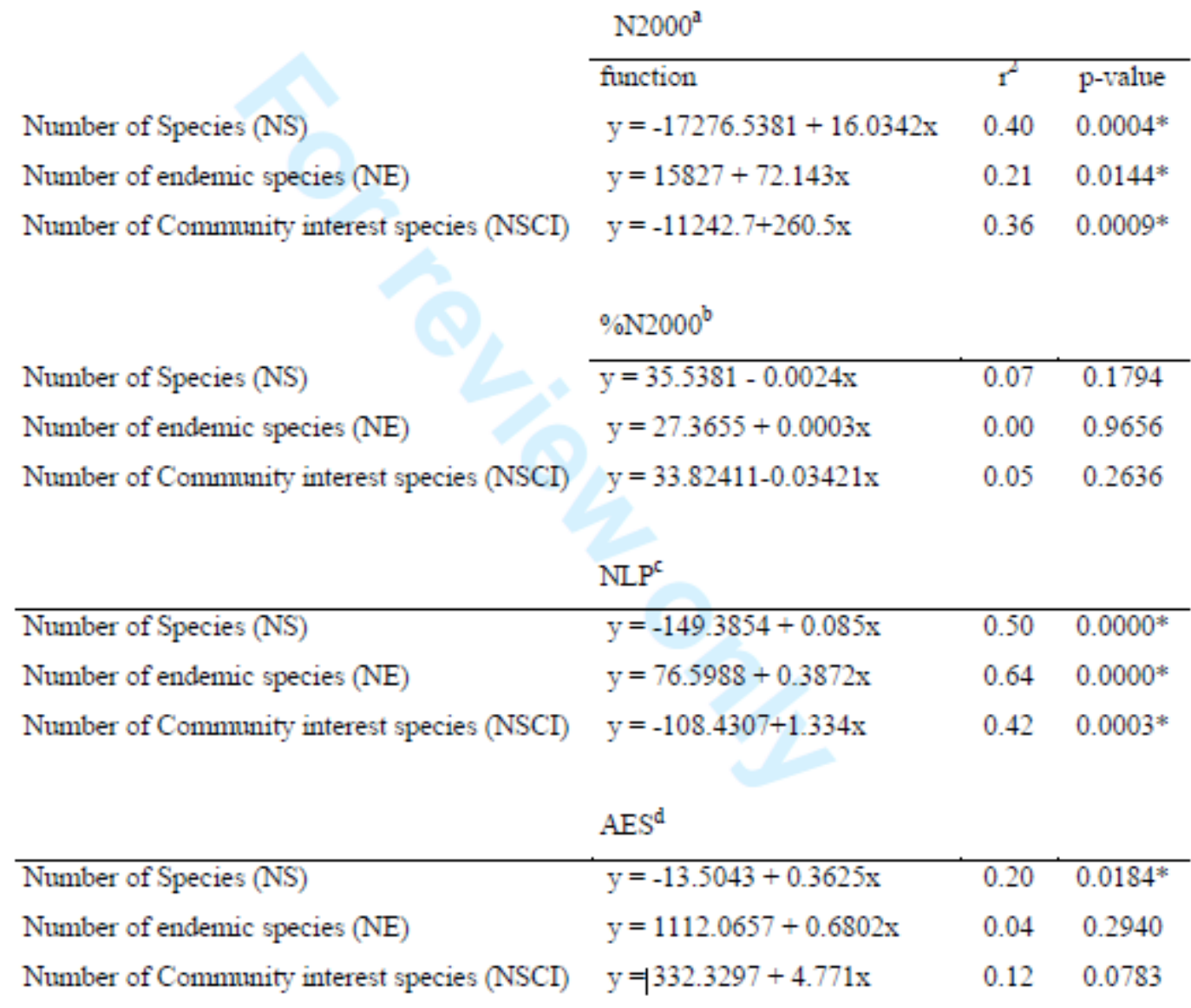

Figure 1. Biodiversity values (NS: total number of species; NE: number of endemic species; NSCI: number of species of Community interest) plotted against resources for biodiversity conservation (surface of Natura 2000 network, public expenditure on agri-environment schemes (AES), and number of LIFE projects). Dashed line represents the Confidence interval of 95\%. Countries falling outside the upper or lower the Confidence interval of $95 \%$ boundary are represented in green and red, respectively (see Supporting Information for country codes).

This article is protected by copyright. All rights reserved. 


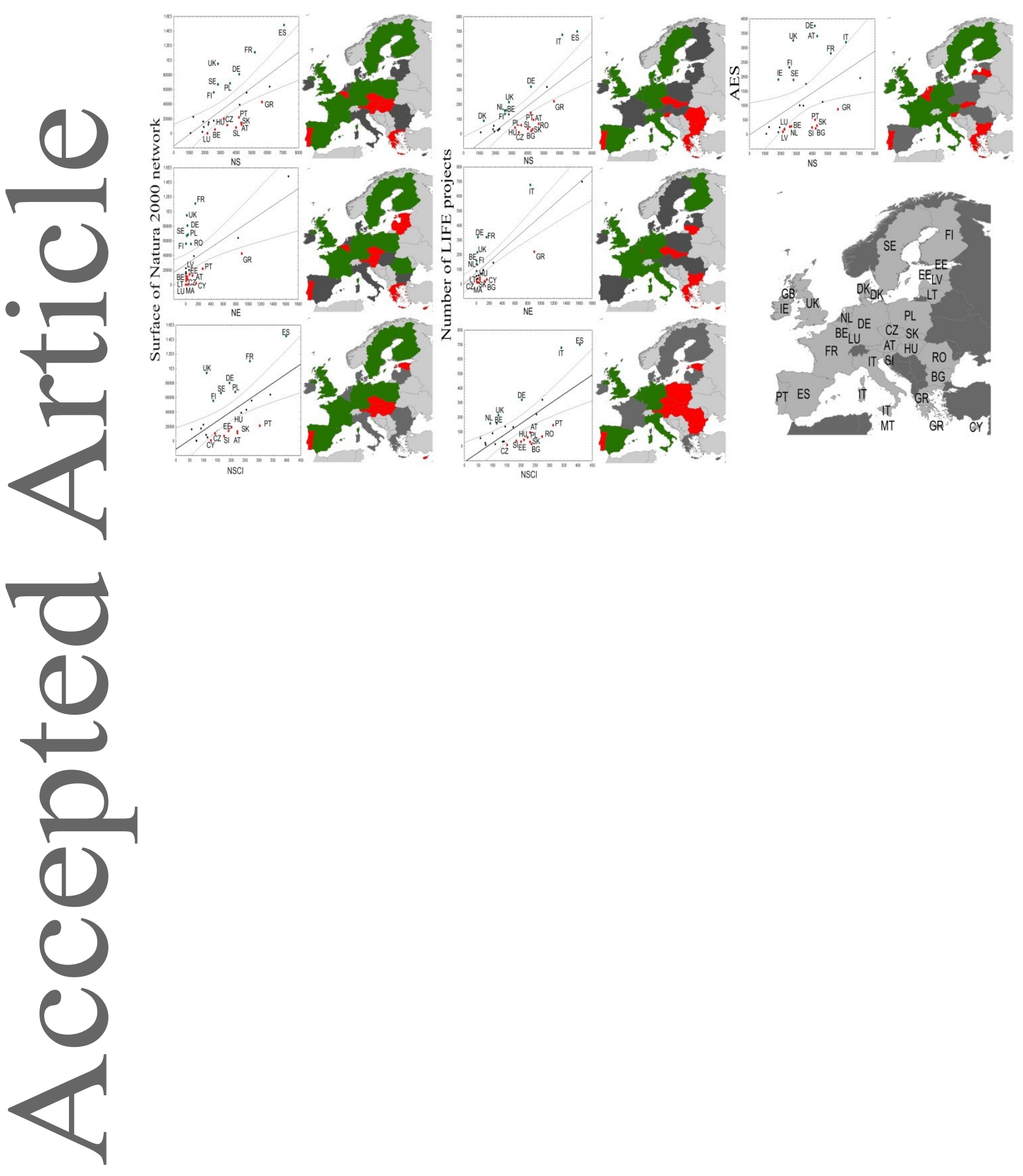

This article is protected by copyright. All rights reserved. 